\title{
Transtorno de personalidade em paciente jovem
}

\section{Personality disorder in a young patient}

Raquel Rebouças de Biasi $\operatorname{Dias}^{1} \mathbb{D}$, Carlos von Krakauer Hübner ${ }^{1}$

\begin{abstract}
RESUMO
Trata-se de um caso de transtorno de personalidade do tipo antissocial que chegou sem diagnóstico prévio à enfermaria de psiquiatria do Conjunto Hospitalar de Sorocaba, trazido por uma queixa de alteração do comportamento e heteroagressividade.

Palavras-chave: transtorno da personalidade antissocial; agressão; adolescente.
\end{abstract}

\begin{abstract}
This paper presents a case of antisocial personality disorder admitted at the psychiatric ward of the Conjunto Hospitalar de Sorocaba without a previous diagnostic. He was brought in by his mother, with the complaint of heteroaggressiveness. Keywords: antisocial personality disorder; aggression; adolescent.
\end{abstract}

\section{INTRODUÇÃO}

A personalidade pode ser definida como as características individuais que correspondem a um padrão persistente de emoções, pensamentos e comportamentos. ${ }^{1}$ Os traços da personalidade são definidores importantes de comportamentos no sentido de que suas manifestações estão associadas a uma variedade importante de indicadores nos níveis individual, interpessoal e social. ${ }^{1}$

A partir disso, um Transtorno da Personalidade (TP) pode ser caracterizado como:

Padrão persistente de experiência interna e comportamento que se desvia acentuadamente das expectativas da cultura do indivíduo, é difuso e inflexível, começa na adolescência ou início da fase adulta, é estável ao longo do tempo e leva a sofrimento ou prejuízo. ${ }^{1}$

É comum que pessoas com TP tenham um repertório limitado de emoções, atitudes e comportamentos para lidar com os problemas e estresse da vida cotidiana, apresentando respostas desadaptativas que levam a sofrimento e/ou prejuízos a si ou aos outros. ${ }^{1}$

Historicamente, o conceito de TP sofreu deslocamentos diversos até chegar à concepção atualmente adotada. ${ }^{2} \mathrm{Na} \mathrm{An}$ tiguidade, a Teoria Humoral de Hipócrates, posteriormente aperfeiçoada por Galeno, foi responsável pela interface que levou em conta os tipos da personalidade e o substrato orgânico do indivíduo. ${ }^{2}$

A Era Moderna dos TP pode ser considerada a partir de 1952, com a publicação do primeiro Manual Diagnóstico e Estatístico de Transtornos Mentais (DSM) pela Associação Americana de Psiquiatria (APA). Nessa versão inicial, as patologias da personalidade tiveram breves descrições e incluíram um amplo campo diagnóstico para o TP antissocial, com subtipos como desvios sexuais, alcoolismo, dependência de drogas e reações dissociais. ${ }^{2}$

Ao longo do desenvolvimento da última edição do DSM, várias revisões foram propostas, com alterações significativas no método de diagnosticar o TP. No entanto, estas não foram incorporadas à seção principal, que manteve a mesma abordagem diagnóstica categorial anterior. ${ }^{2} \mathrm{O}$ modelo multiaxial foi suspenso no DSM- $5^{8}$ com a alegação de que seu uso não era determinante para o direcionamento do diagnóstico do transtorno mental. ${ }^{3}$

As desordens da personalidade podem ser consideradas como um dos transtornos mentais mais complicados de diagnosticar e de tratar. O diagnóstico é dificultado, em parte, pela própria natureza dos sintomas, pouco diferenciados e com fronteiras menos nítidas com a normalidade. Ademais, também há dificuldade pela necessidade de uma avaliação longitudinal e em vários contextos. ${ }^{3}$

${ }^{1}$ Pontifícia Universidade Católica de São Paulo, Faculdade de Ciências Médicas e da Saúde - Sorocaba (SP), Brasil.

Autor correspondente: Carlos von Krakauer Hübner - Pontifícia Universidade Católica de São Paulo, Faculdade de Ciências Médicas e da Saúde, Departamento de Medicina - Rua Joubert Wey, 290 - CEP: 18030-070 - Sorocaba (SP), Brasil - E-mail: psiqinternato@uol.com.br Recebido em 16/10/2017. Aceito para publicação em 06/06/2018. 
Além disso, muitas das características consideradas para o diagnóstico são egossintônicas, ou seja, o indivíduo tem um insight limitado da natureza de suas dificuldades. Sendo assim, em geral, ele não identifica ou não se incomoda com o que considera componentes de "seu jeito de ser" e, por isso, não há iniciativa para, ou há resistência em, procurar avaliação clínica e tratamento especializado. ${ }^{3}$

Observa-se que pacientes com TP tendem a ser atendidos em períodos de crise ou em decorrência de sintomas de depressão, ansiedade e problemas relacionados ao uso de substâncias psicoativas, que representam comorbidades muito prevalentes. ${ }^{4}$ Nesse sentido, o processo diagnóstico pode ser facilitado pela presença de um informante que poderá fornecer relato sobre sua perspectiva dos problemas apresentados pelo paciente ao longo de um período maior e relacionados ao seu funcionamento interpessoal. ${ }^{4}$

\section{RELATO DO CASO}

Paciente de 18 anos, masculino, branco, solteiro, não estuda ou trabalha, sem religião. Nível de escolaridade: ensino fundamental completo.

Com relação a tabagismo, fuma 1 maço/dia há um ano e uso diário de maconha por 18 meses, tendo parado abruptamente há 1 mês. Faz uso de bebidas alcoólicas cerca de 2 ou 3 vezes por semana, em bares perto de onde mora. Ao ser questionado sobre como adquire as drogas para consumo, ele afirma utilizar o dinheiro que ganha do pai ou do avô. Nega furtos ou outro envolvimento criminoso.

Alteração do comportamento e agressividade há 1 dia, com diagnóstico prévio e em tratamento de Transtorno do Déficit de Atenção com Hiperatividade (TDAH) desde os 9 anos de idade. Desde cedo apresenta isolamento social, agitação e dificuldade de relacionamento. Há um dia teve uma discussão com o irmão caçula que não queria deixá-lo entrar em casa e, quando foi contrariado, o paciente começou a quebrar os objetos ao seu redor, mas não chegou a agredir ninguém.

Meses antes, ele diz ter ficado irritado com um cachorro no sítio do avô que ficava andando atrás dele e, por isso, o agrediu e o queimou com cigarro. Afirma ter sido o único episódio de agressão a animais e diz estar arrependido. Agrediu o vizinho (com socos no rosto) e o porteiro do prédio (com pedradas) porque ambos o provocavam e faziam piada dele. Desses episódios não se arrepende, afirmando que ambos mereceram por não gostarem dele.

Ele também coloca que tem péssimo relacionamento com o padrasto, com quem morou desde os 3 anos de idade, e teve vontade de matá-lo mais de uma vez. Entretanto, o máximo que chegou a fazer foi esfaquear a parede. Atualmente mora sozinho em um apartamento pequeno em frente à casa da mãe, mantido pelo pai, com quem tem pouco contato. Nunca morou com seu pai, apenas com a mãe. Seu ambiente familiar é conturbado devido ao temperamento agressivo tanto do paciente, como do marido da mãe, o que resultou em conflitos frequentes, surras e castigos, quando pequeno.
A mãe afirma que o paciente tinha muito ciúme do relacionamento do irmão caçula com o padrasto (pai biológico da criança) e que a maioria das discussões envolviam a "superproteção" e as regalias concedidas ao segundo filho e não a ele. O paciente também apresentou problemas na escola tanto de relacionamento (os colegas o chamavam de louco) quanto de aprendizagem (repetiu o $1^{\circ}$ e o $7^{\circ}$ anos).

Após explanação do tema para o paciente e sua responsável, assim como estabelecidas as regras e sigilos, o mesmo assinou o Termo de Consentimento Livre e Esclarecido.

\section{DISCUSSÃO E CONCLUSÃO}

Dentre os tipos existentes de Transtornos da Personalidade, o que mais se assemelha ao do paciente em questão é o antissocial, por conta da sua incapacidade de se adaptar às normas sociais que governam aspectos do comportamento adulto e adolescente. ${ }^{4}$

Além disso, ele apresenta características clínicas semelhantes a tal diagnóstico, como ausência de ansiedade ou depressão (embora pareça incongruente com a condição desses pacientes), conteúdo mental sem delírios ou outros sinais de pensamento irracional e incapacidade de adesão a um padrão convencional de moralidade. ${ }^{4}$

Outra característica comum nesses pacientes, porém parcialmente presente no paciente relatado, é a falta de remorso dos seus atos, parecendo faltar-lhes consciência. No caso dele, dizia sentir arrependimento apenas da briga com o irmão mais novo e da tortura com o cachorro do avô. Entretanto, das brigas e agressões a quem ele não gostava (vizinhos, porteiro, padrasto), não se arrependia. Ao entrevistá-lo, é possível supor uma afinidade pelos mais frágeis do que ele, como crianças. Fala do irmão com empatia. ${ }^{5}$

Pode ser diferenciado do comportamento ilegal, porque o transtorno antissocial envolve diversas áreas da vida do indivíduo, porém a diferenciação mais difícil é a que envolve abuso de drogas. No caso do paciente, há manifestações desde a infância, porém, sem que houvesse abuso das mesmas. ${ }^{5}$ O diagnóstico não pode ser justificado quando há deficiência mental, mania ou esquizofrenia. ${ }^{5}$

Embora não haja citação na literatura de que Transtorno de Déficit de Atenção/Hiperatividade (TDAH) seja um diagnóstico diferencial para Transtorno de Personalidade antissocial, eles podem aparecer concomitantemente. Como mencionado anteriormente, nosso paciente foi diagnosticado, aos 9 anos de idade, com TDAH. ${ }^{6,7}$

\section{REFERÊNCIAS}

1. Tavares H, Ferraz R, Bottura HML. Transtornos de personalidade. In: Forlenza OV, Miguel EC, editores. Compêndio de clínica psiquiátrica. Barueri: Manole; 2012. p. 511-26.

2. Campos RN, Campos JAO, Sanches M. A evolução histórica dos conceitos de transtorno de humor e transtorno de personalidade: problemas no diagnóstico diferencial. Rev Psiquiatr Clín. 2010;37(4):162-6. http://doi.org/10.1590/S0101-60832010000400004 
3. Sadock BJ, Sadock V. Kaplan \& Sadock: compêndio de psiquiatria. $9^{\mathrm{a}}$ ed. Porto Alegre: Artmed; 2007. p. 852-76.

4. Pereira HS, Araújo APQC, Mattos P. Transtorno do déficit de atenção e hiperatividade (TDAH): aspectos relacionados à comorbidade com distúrbios da atividade motora. Rev Bras Saúde Matern Infant. 2005;5(4):391402. http://doi.org/10.1590/S1519-38292005000400002

5. Mazer A, Macedo BB, Juruena MF. Transtornos da personalidade. Medicina (Ribeirão Preto). 2017;50(Supl. 1):85-97. http://doi.org/10.11606/ issn.2176-7262.v50isupl1.p85-97
6. Polanczyk GV, Rohde LA. Transtorno de déficit de atenção/hiperatividade. In: Forlenza OV, Miguel EC, editores. Compêndio de clínica psiquiátrica. Barueri: Manole; 2012. p. 220-37.

7. DATASUS. CID-10: 60-F69 Transtornos da personalidade e do comportamento do adulto [Internet]. [acesso em 10 set. 2017]. Disponível em: http://www. datasus.gov.br/cid10/V2008/WebHelp/f60_f69.htm

8. American Psychiatric Association. Manual Diagnóstico e Estatístico de Transtornos Mentais: DSM-5. Porto Alegre: Artmed; 2014.

\section{Como citar este artigo:}

Dias RRB, Hübner CK. Transtorno de personalidade em paciente jovem. Rev Fac Ciênc Méd Sorocaba. 2019;21(2):92-4. http://doi.org/10.23925/1984-4840.2019v21i2a10 